\title{
Estimation of Urinary Delta Aminolevulinic Acid Levels in Garage Workers as an Index of Lead Exposure
}

\author{
Sachin A Patharkar ${ }^{1}$, Shalu J Benwal ${ }^{2}$, Alka V Nerurkar ${ }^{3}$, Neelam Patil ${ }^{4}$
}

\begin{abstract}
Background: Lead is the toxic heavy element in the environment. Human exposure to lead and its compounds occurs mostly in lead-related occupations such as car repair, battery manufacturing and recycling, refining, smelting. Lead is a highly poisonous metal affecting almost every organ in the body. Lead inhibits necessary enzymes required for heme synthesis, and this results in increased levels of delta-aminolevulinic acid ( $\delta$-ALA) excretion through urine.

Aim: To estimate the urinary $\delta$-ALA acid levels in garage workers as an index of lead exposure.

Materials and methods: This is a cross-sectional study in Mumbai from different suburban localities. The study was done on 72 garage workers of age group between 18 years and 50 years with their brief history related to lead exposure. Their urine samples were analyzed for $\delta$-ALA by Ehrlich method.

Results: According to our observation, it was found that out of 72 urine samples 19 samples (26.38\%) have urinary $\delta$-ALA levels below reference value ( $<5 \mathrm{mg} / \mathrm{L})$, while 53 samples showed increased urinary $\delta$-ALA levels $(73.61 \%)$; out of these, 45 workers $(84.90 \%)$ fall in the moderate-to-high exposure level category ( 5 or $>5$ to $20 \mathrm{mg} / \mathrm{L}), 8$ workers (15.09\%) fall in the dangerous-very high exposure level category ( 20 or $>20$ to $40 \mathrm{mg} / \mathrm{L}$ ). Conclusion: The prevalence of lead exposure among our study population is $73.61 \%$.

Clinical significance: We conclude that there is high prevalence of lead exposure in garage workers in Mumbai, and necessary precautions need to be taken to avoid it.

Keywords: Blood lead levels, Cross-sectional observational study-original research, Lead, Lead poisoning in garage workers, Urinary delta ( $\delta$ ) ALA. Indian Journal of Medical Biochemistry (2019): 10.5005/jp-journals-10054-0113
\end{abstract}

\section{INTRODUCTION}

Occupational exposure is a major source for lead poisoning in adults. According to the estimates made by the National Institute of Occupational Safety and Health, more than 3 million workers in the United States are potentially exposed to lead in the workplace. ${ }^{1}$ In addition, many other occupational workers like lead miners and smelters, plumbers and fitters, car mechanics, glass manufacturers, construction workers, battery manufacturers and recyclers, firing range instructors, and plastic manufacturers are at risk of lead exposure. ${ }^{2}$ Parents who are exposed to lead at workplaces generally bring lead dust to their home with clothes or on their skin, thus increasing the chances of exposure in their family members including children. ${ }^{3}$

In India and in some other East African countries, "khat" or "tobacco" or "pan masala" chewing at the workplace is a common practice. Workers handle variety of the materials at work places. They do not wash their hands each time. As a result, the various toxic substances, including lead, that have stuck to the hands of these workers might easily get transferred onto the "khat" leaf surface and then ingested with the "khat" by the workers. ${ }^{4}$

Most of the workers have no idea about the toxic metals they might be exposed to; as a result, they pay little attention to protecting themselves from the possible inhalation or ingestion of such toxic substances nor are they given awareness on the issue or advised to take the necessary protective measures. Despite this fact, no serious study has been conducted to assess the blood lead levels (BLL) of people working in auto garages or of workers in other industries that are expected to pose health risks to workers.

\begin{abstract}
${ }^{1-4}$ Department of Biochemistry, Topiwala National Medical College and BYL Nair Charitable Hospital, Mumbai, Maharashtra, India

Corresponding Author: Neelam Patil, Department of Biochemistry, Topiwala National Medical College and BYL Nair Charitable Hospital, Mumbai, Maharashtra, India, Phone: +91 9820314102, e-mail: neelamb99@gmail.com
\end{abstract}

How to cite this article: Patharkar SA, Benwal SJ, Nerurkar AV, et al. Estimation of Urinary Delta Aminolevulinic Acid Levels in Garage Workers as an Index of Lead Exposure. Indian J Med Biochem 2019;23(3):312-315.

Source of support: Department of Biochemistry, TNMC and BYL Nair Charitable Hospital

Conflict of interest: None

The prevention of occupational hazards is far more effective and less costly when considered during the early stages. Lead poisoning among occupationally exposed persons is known to pose serious health problems on the nervous system, heme biosynthesis, kidneys, reproductive system, hepatic, hearing, endocrinal, gastrointestinal, blood pressure, and cardiovascular system. ${ }^{5}$ The effect of lead on heme synthesis is attributed to the inhibition of enzymes involved in heme synthesis, resulting in abnormal concentrations of heme precursors in blood and urine. Essentially, lead interferes with the activity of three enzymes: it indirectly stimulates the mitochondrial enzyme aminolevulinic acid synthetase; it directly inhibits the activity of the cytoplasmic enzyme aminolevulinic acid dehydratase; and it interferes with the normal functioning of intramitochondrial ferrochelatase. ${ }^{6}$

() The Author(s). 2019 Open Access This article is distributed under the terms of the Creative Commons Attribution 4.0 International License (https://creativecommons. org/licenses/by-nc/4.0/), which permits unrestricted use, distribution, and non-commercial reproduction in any medium, provided you give appropriate credit to the original author(s) and the source, provide a link to the Creative Commons license, and indicate if changes were made. The Creative Commons Public Domain Dedication waiver (http://creativecommons.org/publicdomain/zero/1.0/) applies to the data made available in this article, unless otherwise stated. 


\section{Aims and Objectives}

The present study was conducted to find out the prevalence of lead poisoning among the garage workers, in a suburban Mumbai, by estimating the urinary $\delta$-ALA levels as an index of lead exposure and to educate the community about health hazards of lead exposure and protection from it.

\section{Materials and Methods}

This is a cross-sectional pilot observational study in Mumbai suburban localities. Urine samples of 72 garage workers with due informed written consent were collected with their names, area, age, and daily working details, by random sampling with due ethical considerations. Samples were collected from different locations in Mumbai. Urine samples were collected in $15-\mathrm{mL}$ plastic containers, covered with brown paper, exercising standard precautions. First morning midstream urine samples were collected after local area cleaning. This study was designed and carried out in the Department of Biochemistry, Topiwala National Medical College and BYL Nair Charitable Hospital, Mumbai 400008, during the period May 2016 to May 2018.

Sample size was decided on the basis of formula: $n=4 p q / / 2$ where $I$ is permissible error in the estimation of new statistics, $p$ is positive character, and $q$ is $1-p$. Permissible error or prevalence found from old thesis of own college, and national journals.

Their urine samples were analyzed for $\delta$-ALA by Ehrlich method in which acidic urine reacts with $n$-butanol and $\delta$-ALA was converted to its pyrrole at $\mathrm{pH}$ 6.8. The pyrrole reacted with Ehrlich's reagent to form red color, which was extracted with chloroform and read colorimetrically. ${ }^{7}$ Comparing the method with other methods like ion exchange chromatography, the method discussed by Tomokuni et al., it is found that this method being colorimetric is easy, rapid, and accurate as all interfering substances are removed by butanol extraction. ${ }^{8,9}$ The procedure is standardized, and graph is plotted prior to use on subjects.

\section{Results}

According to the reference value, i.e. $(<5 \mathrm{mg} / \mathrm{L})$, the result is divided into categories (higher and lower than reference values), subdivided as high exposure level ( 5 or $>5$ to $20 \mathrm{mg} / \mathrm{L}$ ) and dangerous-very high exposure level ( 20 or $>20$ to $40 \mathrm{mg} / \mathrm{dL}$ ). ${ }^{10-12}$

According to our observation, it was found that out of 72 workers, 53 (73.61\%) workers were categorized as above reference level with mean \pm SD value of $12.32 \pm 5.83$ and remaining-19 (26.38\%) were considered as below reference level with mean \pm SD value of $3.08 \pm 0.71$ (Table 1). The prevalence of lead exposure among our study population is $73.61 \%$.

Out of the above-calculated 53 workers (ALA above reference level)-45 (84.90\%) were categorized as acceptable-high

Table 1: Statistical parameters

\begin{tabular}{lll}
\hline & $\begin{array}{l}\text { ALA below reference } \\
\text { level }(<5 \mathrm{mg} / \mathrm{L})\end{array}$ & $\begin{array}{l}\text { ALA above reference } \\
\text { level }(5 \text { or }>5-20 \\
\mathrm{mg} / \mathrm{L})\end{array}$ \\
\hline $\begin{array}{l}\text { Statistical parameter } \\
\text { No. of samples }\end{array}$ & 19 & 53 \\
$\begin{array}{l}\text { expontage of } \\
\text { Mean }\end{array}$ & $26.38 \%$ & $73.61 \%$ \\
Standard deviation & \pm 0.71 & 12.32 \\
\hline
\end{tabular}

exposure level and 8 (15.09\%) were categorized as dangerous—very high exposure level.

From the above table 1, it is inferred that working in unhygienic conditions with tobacco- and pan-eating habits contributes to leading causes of lead exposure.

\section{Statistical Analysis}

The main outcome parameter urinary $\delta$-ALA level is a continuous scaled data, to find out the prevalence of lead exposure we converted this data into categorical data depending upon the reference range of urinary $\delta$-ALA levels. So calculated only percentage of high exposed individuals. No other statistical test is required.

Standard error of proportion S.E.P. $=\sqrt{\frac{p q}{n}}=\sqrt{\frac{74 \times 26}{72}}=5.16$.

So, $95 \%$ confidence interval $68.45-78.77$.

\section{Discussion}

In this study, we detected the lead exposure by measuring urinary marker, i.e., $\delta$-ALA levels. The activity of $\delta$-ALA dehydratase is markedly decreased by lead, by which there is an increase in $\delta$-ALA excretion. ${ }^{13}$ By measuring the urinary $\delta$-ALA, we can detect the lead exposure. ${ }^{14,15}$ The quantitative estimation of $\delta$-ALA is basically based on the well-known reactivity of pyrroles with $p$-dimethylaminobenzaldehyde. Elevated ALA concentrations were indicated by a reddish color in chloroform, while normal concentrations usually gave only faint yellow or faint red color. Urine usually contains many substances, which react with Ehrlich reagent to form red color, and it also contains some substances that interfere with the formation of pyrroles and aldehydes. These substances are removed by $n$-butanol extraction. Small amounts of Ehrlich-positive substances, which escaped the $n$-butanol extraction, formed a red color with the addition of Ehrlich's reagent, but this never entered into the chloroform phase. The only substance that behaved like ALA was aminoacetone. Urinary aminoacetone levels in lead poisoning have been reported to be entirely normal. The specificity is good enough to use this method for screening lead exposure. Random urine specimens from normal individuals contain in the order of $0.2 \mathrm{mg} \delta$-ALA per $100 \mathrm{~mL}$ urine.

This study considered urinary excretion of $\delta$-ALA as a surrogate marker of blood lead in garage workers; owing to lack of facilities to measure BLL, $\delta$-ALA is excreted normally in small amounts in urine, but the levels increase with lead exposure. Previous studies reported a five-fold increase in urinary excretion of $\delta$-ALA following lead intoxication. ${ }^{16}$ This rise in concentration of $\delta$-ALA during lead exposure is a function of primarily decreased activity of enzymes involved in the heme synthetic pathway. This inhibition would then result in increased levels of $\delta$-ALA in the blood and plasma, eventually leading to increased $\delta$-ALA urinary excretion.

Increased urinary $\delta$-ALA levels are obtained from about $73.61 \%$ of exposed workers, which is a clear indicator of cumulative lead exposure (Table 1 and Fig. 1) and appears to be directly related to the duration of employment at the work units, since almost $95 \%$ of them had 12 and above years of experience (Table 2). Increased urinary $\delta$-ALA levels found in exposed subjects and predominantly in the age group 21-30 years followed by $31-40$ years (Table 3 ) in the present study. This might be the impact of low-level long-term lead exposure at the work units and reinforces the notion that $\delta$-ALA can serve as a surrogate marker for lead exposure. Evidence for 


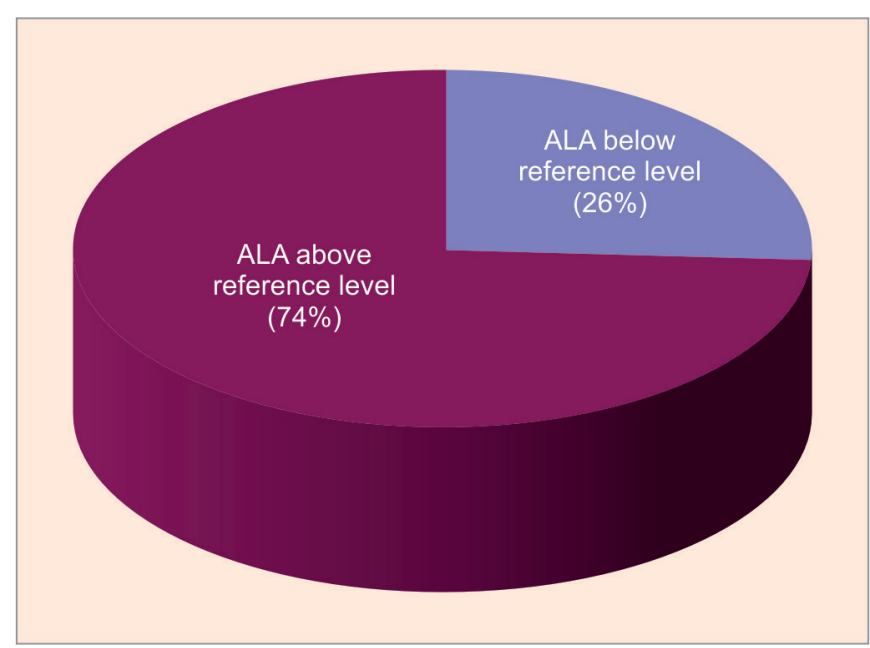

Fig. 1: Pie diagram showing percentage of exposure for below and above levels of $\delta$-ALA according to reference value

Table 2: Duration of exposure/employment (for workers who fall in above reference category)

\begin{tabular}{lc}
\hline Duration of exposure/employment & Number of workers \\
\hline$>12$ years and more & 49 \\
$>6-10$ & 5 \\
$<4$ years & 18 \\
\hline
\end{tabular}

Table 3: Age distribution

\begin{tabular}{lll}
\hline Age in years & $\begin{array}{l}\text { Urinary } \delta \text {-ALA levels } \\
<5 \mathrm{mg} / \mathrm{dL}\end{array}$ & $\begin{array}{l}\text { Urinary } \delta \text {-ALA levels } \\
>5 \mathrm{mg} / \mathrm{dL}\end{array}$ \\
\hline $15-20$ & 5 & 5 \\
$21-30$ & 9 & 24 \\
$31-40$ & 3 & 15 \\
$41-50$ & 2 & 7 \\
$51-55$ & - & 2 \\
\hline
\end{tabular}

the contribution of lead exposure to elevated urinary $\delta$-ALA levels comes from the observation that $26.38 \%$ of less-to-non-exposed subjects (as per the details obtained from the workers) exhibited below reference level range, and none of them had high levels (Table 1 and Fig. 1). This observation excludes the possibility that other factors might have contributed to the observed high levels of $\delta$-ALA in exposed subjects. Chronic lead exposure as a culprit for higher $\delta$-ALA levels was also corroborated by the observation that levels vary with duration of employment (Table 2). Urinary $\delta$-ALA levels in the workers who had served for many years were higher than in those served for few years and below. This finding is consistent with other reports that show urinary $\delta$-ALA of especially lead workers increases with an increase in the duration of exposure. ${ }^{17}$

After this study, the results were explained to the participants and necessary precautions were suggested, which include avoiding the use of lead-based containers and stuffs, and eating or chewing things like tobacco, regularly checking the BLL, washing their hands and handy equipment's regularly, to stop wrapping foods in newspapers, to clean themselves up before leaving the workplace to avoid contamination at home, etc. (Table 4). Hence, by exercising necessary precautions we can reduce the lead exposure to an extent as prevention is always better than cure.
Table 4: Daily practices of the study population

\begin{tabular}{ll}
\hline Habits & Percentage \\
\hline Working in unhygienic conditions & 95 \\
Tobacco and pan eaters & 90 \\
Alcohol consumers & 75 \\
\hline
\end{tabular}

\section{Future Scope}

- Measurement of blood ALA levels to compare with urinary ALA level as an index of lead exposure.

- Measurement of hemoglobin and correlation with urinary ALA level.

- Measurements of BLL and correlate it with urinary ALA level.

- To measure the contribution of alcohol consumption in the increasing levels of lead exposure.

\section{Conclusion}

The study sample represents the local and professional garage workers and welders. It is important to make them aware because they might not be aware whether they are suffering from lead exposure or not. In this study, the population age group is 15-50 years and 72 samples were collected from 7 different areas in and around Mumbai. The results obtained from the study are $73.61 \%$ (above the reference value) that is more than half of the population of workers have already been exposed to. It is now our duty to save the rest of the population from lead exposures, and therefore, it is important to educate the population with proper precautions.

\section{References}

1. Staudinger KC, Roth VS. Occupational lead poisoning. Am Fam Physician 1998 Feb;57(4):719-726.

2. Sanborn MD, Abelsohn A, Campbell M, et al. Identifying and managing adverse environmental health effects: 3 . Lead exposure. CMAJ 2002;166:1287-1292.

3. Watts J. Lead poisoning cases spark riots in China. Lancet 2009 Sep;374(9693):868. DOI: 10.1016/S0140-6736(09)61612-3.

4. Pala K, Turkkan A, Gucer $S$, et al. Occupational lead exposure: blood lead levels of apprentices in Bursa, Turkey. Ind Health 2009 Jan;47(1):97-102. DOI: 10.2486/indhealth.47.97.

5. World Health Organization Regional Office for Europe Air Quality Guidelines. Copenhagen; 2001.

6. Massaro EJ. Handbook of Human Toxicology. New York: CRC Press; 1997.

7. Wada O, Toyokawa K, Urata G, et al. A simple method for the quantitative analysis of urinary delta-aminolevulinic acid to evaluate lead absorption. Br J Ind Med 1969;26(3):240-243.

8. Cramer K, Selander S. Studies in lead poisoning: Comparison between different laboratory tests. Br J Ind Med 1965;22(4):311-314. DOI: 10.1136/oem.22.4.311.

9. Tomokuni K, Ogata M. Simple method for determination of urinary 5-aminolevulinic acid as an index of lead exposure. Clin Chem 1972; 18(12):1534-1536.

10. Lane RE, Hunter D, Malcolm D, et al. Diagnosis of inorganic lead poisoning: A statement. Br Med J 1968;4(5629):501. DOI: 10.1136/ bmj.4.5629.501.

11. Strayer DS, Rubin E. Environmental and Nutritional Pathology In: Rubin R, Strayer DS, Rubin E, McDonald JM ed. Rubins pathology; Clinicopathologic Foundations of Medicine. 5th ed., Lippincot Williams \& Wilkins; 2008. p. 267.

12. King M, Ramachandran V. Kirk-Othmer encyclopedia of chemical technology, 4th ed, New York, NY: John Wiley \& Sons; 1995. pp. 69-113. 
13. Shenoi RP, Khandekar RN, Jayakar AV, et al. Sources of lead exposure in urban slum school children. Indian Paediatr 1991;28: 1021-1027.

14. Tanabe Y. Metabolism of delta-aminolevulinic acid (ALA) and porphobilinogen in lead poisoning. I. Amounts of ALA and PBP in the urine and blood. Jap J Nat Health 1959;28:386-397.
15. Lin-Fu JS. Lead poisoning in children. H.E.W. Child. Bur. Pub. No. 452, U.S. Govt. Printing Office, Washington, D.C.; 1967.

16. Bauer JD. Clinical Laboratory Methods. St. Louis Missouri: The C.V. Mosby Company; 1982.

17. Lee BK. Occupational lead exposure of storage battery workers in Korea. Br J Ind Med 1982 Aug;39(3):283-289. DOI: 10.1136/oem.39.3.283. 